\title{
El método científico y las ciencias de la salud
}

\author{
Francisco-Javier Castro-Molina \\ Editor Jefe de la Revista Española de Enfermería de Salud Mental (REESME). AEESME. \\ Escuela de Enfermería Nuestra Señora de Candelaria (Universidad de La Laguna). Santa Cruz de Tenerife, España. \\ Contacto: Francisco-Javier Castro-Molina / javier.castro.96@ull.edu.es \\ Fecha de recepción: 28 de mayo de 2017 / Fecha de aceptación: 1 de julio de 2017
}

Saber y ciencia son palabras homólogas. Mientras el saber es visto como el conocimiento profundo de una ciencia o arte, la ciencia en sí es definida como un sistema coherente y racional de conocimiento que concluye en demostraciones empírico-lógicas valiéndose de un considerable abanico de premisas definitorias. Pero no todos los saberes pertenecen a la ciencia. El sentido común es aquel saber o creencia que está presente en el individuo y que es compartido por una comunidad que lo concibe como lógico y válido. Es decir, la capacidad natural de juzgar los acontecimientos acaecidos de forma razonable. Pero ¿qué tipo de saber es el que podemos considerar como científico? Debemos tener presente en todo momento que la ciencia es un conocimiento teórico demostrable a través de la prácticatécnica que requiere de una sistematización rigurosa y crítica.

Históricamente, la Revolución Científica vio la luz durante el Renacimiento, desde mediados del siglo XVI hasta finales de siglo XVII, estableciéndose así una línea divisoria entre la aportaciones dadas por la filosofía y la ciencia. Son las ciencias empíricas las que establecieron rasgos específicos y autónomos en su organización, lo que fue el germen del método científico. Este método de investigación usado principalmente para la producción de conocimiento de las ciencias fue diseñado por primera vez por Francis Bacon (1561-1626). Para él, el conocimiento del mundo, libre de todo prejuicio y de las falsas ideas, debía nacer en la observación, ayudándose de la experiencia para "leer la naturaleza". Galileo Galilei (1564-1642), a diferencia de Bacon, empleó dos caminos descoordinados hasta entonces, la vía teórica y la experimental, donde las herramientas fundamentales fueron las matemáticas y no solo la deducción racional (método hipotético-deductivo). Pero es con Isaac Newton (1642-1727) con quien culmina la obra. Parte de una interpretación mecanicista del mundo, apoyándose también en las matemáticas y la experiencia. Mediante el estudio de las leyes, logró así abandonar la hipótesis metafísico-teológica que procuraba dar una interpretación lógica del universo, lo que definió a posteriori la ciencia moderna.

Varios siglos más tarde, el filósofo Bertrand Russell (1872-1970), en su obra titulada La perspectiva cientifica, publicada en 1969, definió el método científico como la observación de aquellos hechos que permiten al observante descubrir las leyes comunes o generales que los gobiernan. Añade además que "para llegar a establecer una ley científica existen tres etapas principales: la primera consiste en observar los hechos significativos; la segunda en sentar hipótesis que, si son verdaderas, expliquen aquellos hechos; la tercera en deducir de estas hipótesis consecuencias que pueden ser puestas a prueba por la observación". Añade además que "si las consecuencias son verificadas, se acepta provisionalmente la hipótesis como verdadera, aunque requerirá ordinariamente modificación posterior, como resultado del descubrimiento de hechos ulteriores". Por otro lado, la enfermera Francisca Hernández de Canales (†1989), en la segunda edición de su obra póstuma titulada Metodología de la Investigación. Manual para el desarrollo de personal de salud, lo define como "el procedimiento que se aplica al ciclo completo de la investigación en la búsqueda de soluciones a cada problema del conocimiento, siendo un proceso que exige sistematización del pensamiento buscando una manera ordenada de desarrollar el pensamiento reflexivo y la investigación".

¿Y qué sucede con las ciencias de la salud? ¿Existe un método científico en este campo que permita desarrollar un proceso de investigación coherente? Cuando el filósofo Mario Bunge (1919) hace alusión al método científico en las ciencias de la salud (La investigación científica, su estrategia y la filosofia, 1969), diferencia "entre el método general de la ciencia y los métodos especiales de las ciencias particulares", aclarando que lo "primero es que el método científico constituye un modo de tratar problemas intelectuales, no cosas ni instrumentos consecuentemente, pudiendo utilizarse en todos los campos del conocimiento; y segundo, que la naturaleza del objeto en estudio dicta 
los posibles métodos especiales del tema o campo de la investigación correspondiente, el objeto o sistema de problemas y la técnica, yendo ambas de la mano". Cuando acercamos el método científico a la clínica, encontramos que existe un estudio de los individuos enfermos, y no en sí de la propia enfermedad. Este estudio es el que se materializa en generalidades de carácter teórico, conocimientos que se aglutinan en áreas como la clínica, la patología o la semiología. Y son las particularidades de los individuos las que obligan a un estudio nominativo, surgiendo así un método científico aplicado o, lo que es lo mismo, el método clínico.

Al centrar nuestra mirada en la enfermería, descubrimos que esta disciplina no es ajena a todo esto. Existe en ella un método científico definido por una serie de pasos correlativos e interconectados que buscan el equilibrio del individuo sano con el medio en el que está inserto; en cambio, en el sujeto enfermo busca el regreso a la armonía física, psíquica, social y espiritual. Según la enfermera Patricia Iyer (1947), el proceso de atención de enfermería, PAE, es el método científico de los "cuidadores profesionales". Está compuesto por una serie de etapas claramente definidas, ordenadas y jerarquizadas, que delimita a cinco: valoración, diagnóstico, planificación, realización (ejecución) y evaluación. El PAE emplea técnicas y procedimientos propios que buscan ejecutar razonamientos para dar solución a los problemas de salud que presenta el individuo, la familia y la comunidad, basándose en los principios del método universal materialista dialéctico del conocimiento.

Como diría Shulman en 1986: "El conocimiento no crece de forma natural e inexorable. Crece por las investigaciones de los estudiosos (empíricos, teóricos, prácticos) y es por tanto una función de los tipos de preguntas formuladas, problemas planteados y cuestiones estructuradas por aquellos que investigan". 